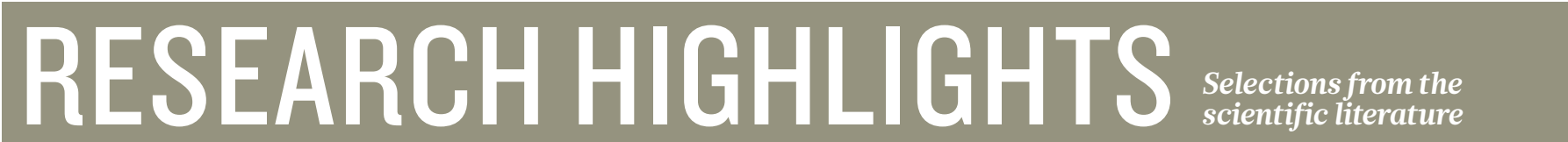

ECOLOGY

\section{Mosquitoes battle for territory}

Competition from an invasive species has resulted in declining numbers of a resident US mosquito during the past few decades, but the resident looks to be evolving resistance to the invader's tactics.

The Asian tiger mosquito (Aedes albopictus) arrived in and spread throughout the southeastern United States in the 1980s. It outcompetes the resident yellow-fever mosquito (Aedes aegypti) through satyrization - the invasive males mate with resident females but prevent the females from producing offspring. Irka Bargielowski and her colleagues at the University of Florida in Vero Beach exposed A. aegypti females to A. albopictus males in cages and looked for evidence of insemination. Females from regions where the two species have lived together for the past 20 years were less likely to be inseminated than were those from areas that have not been invaded.

The results show a potential for the recovery of yellow-fever mosquito populations, the authors say. Proc. Natl Acad. Sci. USA http://dx.doi.org/10.1073/ pnas.1219599110 (2013)

\section{MICROBIOLOGY}

\section{The bacterial} alchemist

A species of bacterium forms tiny nuggets of gold to combat the toxic effects of the dissolved form of the element.

The bacterium Delftia acidovorans lives in extensive communities - known as biofilms - that coat

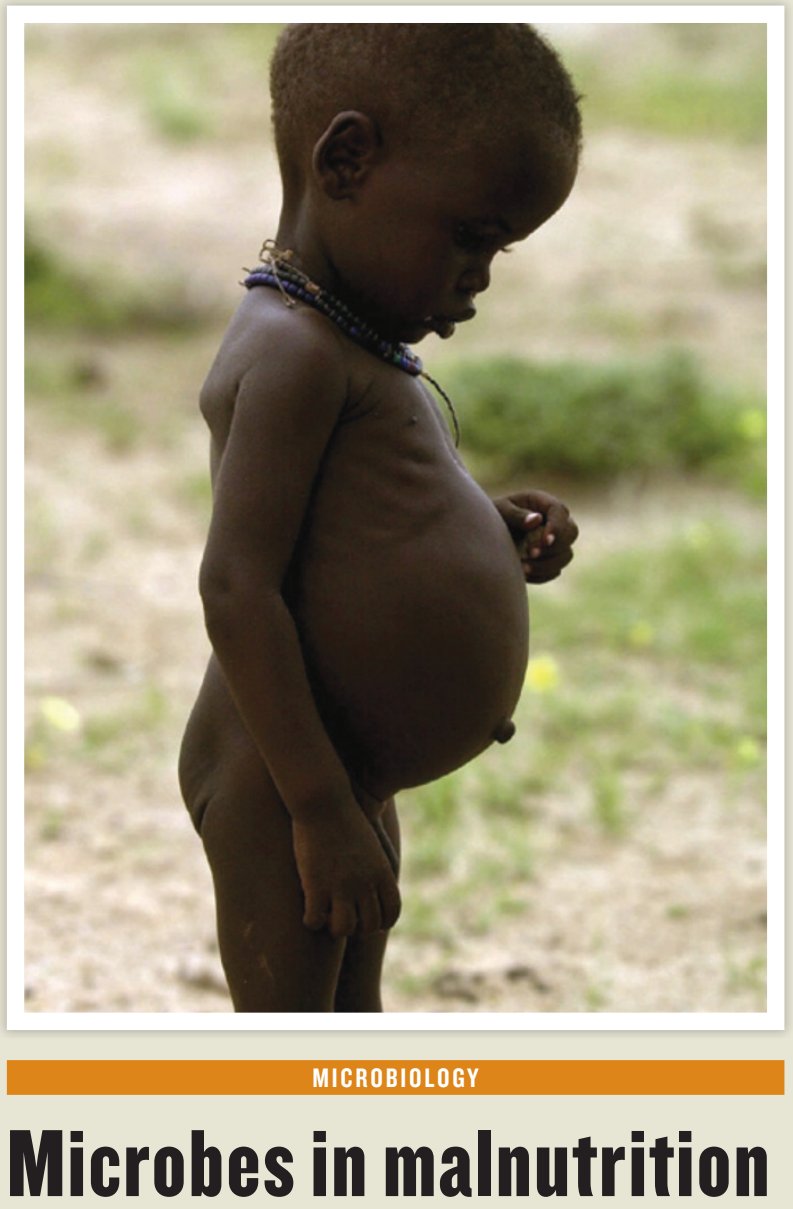

More than a million children around the world die from malnutrition each year, but the condition does not result from diet alone - the make-up of microbes in the gut also has a role.

A team led by Jeffrey Gordon at Washington University in St Louis, Missouri, studied 317 pairs of twins in Malawi. Of these, the authors identified pairs in which one twin had developed a form of severe acute malnutrition called kwashiorkor (pictured). The microbial profiles of these malnourished twins differed from those of their healthy siblings. When both children received therapeutic diets, the malnourished twins' microbiota began to resemble that of their healthy siblings, but it reverted when the children returned to traditional Malawian foods.

The findings could explain the apparent benefit of using antibiotics to treat kwashiorkor, a regime investigated by Mark Manary, also at Washington University in St. Louis, and his group. They conducted a trial with 2,767 Malawian children including those in Gordon and co-workers' study - in which all children received therapeutic diets and some were treated with antibiotics. Of those given the antibiotic cefdinir, $4.1 \%$ died, compared with $7.4 \%$ of the children who received a placebo. Science 339, 548-554 (2013); New Engl. J. Med. 368, 425-435 (2013) gold nuggets. A team led by Nathan Magarvey at McMaster University in Hamilton, Ontario, exposed the microbe to a gold solution and discovered that gold particles formed outside the bacterial membrane. Genomic and biochemical analysis revealed that the microbe secretes a peptide, called delftibactin, that binds to gold ions to form gold particles. Strains in which the genes involved in producing delftibactin were inactivated showed decreased growth in the presence of soluble gold, suggesting that the peptide detoxifies gold ions.

Nature Chem. Biol. http://dx.doi. org/10.1038/nchembio.1179 (2013)

For a longer story on this research, see go.nature.com/dtahlh

\section{ATMOSPHERIC SCIENCE}

\section{Jet-stream shifts linked to ozone}

Antarctic ozone depletion, rather than rising greenhouse gas levels, is the prime culprit for the shifting jet stream in the Southern Hemisphere, a study using observational data has found - supporting previous modelling results.

The westerly jet stream has been shifting southward for the past few decades, affecting weather and climate. Sukyoung Lee and Steven Feldstein at Pennsylvania State University in University Park analysed data on four different wind patterns that fluctuate on short timescales. They found that ozone loss contributes about $50 \%$ more than greenhouse gases towards the jet-stream changes.

Alterations in the westerly jet stream during the summer have been linked to variations in rain patterns and storm locations.

Science 339, 563-567 (2013) 